DOI: 10.15587/2706-5448.2021.229673

Article type «Reports on Research Projects»

\section{Sergii Boichenko, Anna Yakovlieva, Utku Kale, András Nagy}

\title{
ANALYSIS OF TECHNOLOGICAL POTENTIAL FOR UTILIZATION OF WASTE AVIATION LUBRICATING MATERIALS
}

The object of research is technologies for waste aviation oils and lubricants recycling and utilization. The work is devoted to the analysis of the current state and the assessment of the technological potential in the field of processing and disposal of aviation lubricants. The current state and dynamics of the market for the production and consumption of aviation lubricants are considered. The main properties and functions of aviation oils and lubricants are analyzed, the main technical requirements for them are formulated. A complex of physical and chemical processes that occur in lubricants during their operation and long-term storage, and lead to a loss of their quality, is considered. It is shown that the main factors of quality deterioration are high-temperature destruction, oxidation, polymerization and condensation of hydrocarbons, mixing with fuel, and pollution with inorganic compounds. The main ecological as well as economic problems associated with the accamulation of waste lubricants are considered, their negative impact on the components of the environment and human health is described. So, the main negative effects are associated with their improper storage, discharge into water bodies or soils, as well as with their burning and the formation of toxic emissions. On the basis of this, the need for the development and implementation of integrated technologies for the disposal of waste lubricating materials is shown. The main directions, methods and technologies that are used for their utilization are presented. So, depending on the composition, quality and properties of waste lubricants, technologies for restoring their quality, processing technologies using them as raw materials for the production of similar petroleum products, technologies for obtaining low-quality fuels for stationary equipment based on them can be used. It is shown that the development and application of effective technologies for the disposal of used lubricants has a number of positive effects: minimization of the negative impact on the environment, savings and expansion of oil resources for the production of commercial petroleum products, and, as a result, saving money.

Keywords: aviation lubricants, quality change, waste lubricants, waste oil mixtures, quality restoration.

\section{How to cite}

Boichenko, S., Yakovlieva, A., Kale, U., Nagy, A. (2021). Analysis of technological potential for utilization of waste aviation lubricating materials. Technology Audit and Production Reserves, 2 (1 (58)), 26-32. doi: http://doi.org/10.15587/2706-5448.2021.229673

\section{Introduction}

It is well known that lubricants used in the air transport are set to significantly different performance requirements comparing to other industries [1]. At the same time, these requirements also change as the aircraft engine and airframe designs change. So, as aircraft equipment evolves, so do the lubricants [2].

From the studies [3, 4] it is known about a significant difference in operation of engines and, thus, use of lubricants, on military and civil aircrafts. Jet engines on military aircrafts are removed, cleaned, disassembled and inspected, and parts are replaced after on the airframe and operating for a little under 2,000 hr. However, on a Boeing 737-800 (USA) it's two CFM56-7B engines (FranceUSA) are left on the airframe for over $20,000 \mathrm{hr}$ without being removed [3]. Maintenance is one while the engine is fastened to the airframe. It is clearly seen that period of lubricants use, removal and change is completely different. These peculiarities respectively influence the amounts of waste aviation lubricant formation $[5,6]$. Authors of $[7,8]$ state that rapid development of aviation sector causes increasing the volumes of commercial aviation lubricants production. Consequently, such tendency determines formation of waste aviation oils and lubricants, which are created in a result of intensive operation or long-term storage.

However, according to $[8,9]$ accumulation, storage and unproper disposal of waste oils and lubricants have strong negative impact on environment - atmosphere, soil and water and also human health. According to [10] only the pollution of water with waste petroleum oils is $20 \%$ of the total man-made pollution, or $60 \%$ of pollution by petro- 
leum products. Combustion of waste oils sometimes creates even more complex environmental problems than waste oils themselves. This problem stimulates scientist to develop rational and environmentally safe methods for waste oils utilization [11]. Implementation and use of such technologies may have number of benefits: reduction of negative impact on environment, extending raw materials for commercial oil products production and additional economical profit.

Summarizing the abovementioned, disposal of waste oils is an important scientific and technical problem and development of efficient and environmentally safe technologies for waste oils disposal is of high importance.

Thus, the object of research is technologies for waste aviation oils and lubricants recycling and utilization.

The study is aimed on analyzing the existing technological potential for waste aviation lubricating materials disposal and considering the most rational technologies for its utilization.

\section{Methods of research}

For the given study the complex of scientific research methods are sued:

- method of statistical analysis was used for studying the modern situation at the market of aviation lubricants production and formation of waste aviation lubricants; - generalization method was used for description of properties and technical requirements to commercial aviation lubricants;

- method of classification was used to characterize existing technologies for waste oils and lubricants disposal; - methods of systematization and generalization were used for considering the most feasible and environmentally safe way for waste aviation oils disposal.

\section{Research results and discussion}

3.1. Aviation lubricants market overview. The global aviation lubricants market size is projected to grow from an estimated 2.0 billion USD in 2020 to 2.9 billion USD by 2025, at a CAGR of $7.2 \%$ during the forecast period [7]. During last decade, air travel has become more accessible to people due to the availability of low-cost flights, along with the increased frequency of flights and connectivity of airports. Airlines are expanding their commercial fleets, especially in emerging countries such as India and China, and are growing operating hours of aircraft to increase profitability. These large and growing fleets promote the growth of the aviation lubricants market, globally [12].

The main driver of the aviation lubricants market is rapid growth of the commercial and military aircraft fleet in various countries. There is tremendous growth in the fleet size of commercial aircraft, including transport aircraft, in various countries. This is connected to the rise in demand for air travel globally, especially in the emerging economies of Asia Pacific and the Middle East. At the same time, several countries such as the US, Russia, China, and the UK are also increasing their military fleet. The growth of the aircraft fleet and aircraft deliveries is drives the market for aviation lubricants [7, 12].

Such factor as contamination is considered to be a restraint for aviation lubricants market development. Contaminated oil can be disastrous to engine operation. Lubricating oils can be contaminated through operational conditions (dusty or sandy places, or high operating temperatures), faulty maintenance practices, and part failures. An example of harsh operational contamination is carbon. The pieces of carbon are usually not hard enough or large enough to cause failure of pumps. However, they may clog small filters or nozzles. The presence of sand, dirt, and metallic particles in the lube system is another source of operational contamination [7, 12].

Today, airline operators require light components and materials to reduce the overall weight of the aircraft to increase efficiency. Thus, low-density lubricants create new opportunities for lubricants producing industry. Operators highly desire low-density fluids such as Exxon HyJet IV-A plus as they possess unique mechanical properties. These lubricants reduce the repairing cost and enhance equipment life. Hence, there is a great opportunity for manufacturers of aviation lubricants to enter the low-density lubricant market segment [3, 9, 12].

The most challenging issue for the industry is to provide operating capability of lubricants under extreme conditions. Hydraulic fluid in an aircraft operates at a pressure of more than 204 atm in commercial aircraft, and more than $272 \mathrm{~atm}$ in military aircraft. In some modern aircraft, the operating pressure of the hydraulic fluid can even reach $340 \mathrm{~atm}$. Designing and manufacturing fluids that perform efficiently at such demanding pressure is extremely challenging. Lubricants need to function efficiently at very high temperatures and also retain their chemical characteristics over a wide range of temperatures [13, 14].

Typically, engine oils, hydraulic fluids, greases, and special lubricants and additives are the types of aviation lubricants. The engine oil is estimated to take the largest share in the aviation lubricants market. The piston and turbine engine oils are designed to improve the performance of aircraft engines at extremely high temperatures. The growth of engine oil can be attributed to its high consumption during flight hours and the rise in commercial and military aircraft fleets, globally [13].

The commercial aviation segment accounted for the largest share of the aviation lubricants market in 2020 commercial aviation, military aviation, and business and general aviation. The rising air passenger traffic and an increase in the commercial aircraft fleet, especially in emerging economies, are driving the growth of the commercial aviation segment of the aviation lubricants market across the globe [7, 12].

Based on end user type, the aviation lubricants market is segmented into OEM and Aftermarket. The aftermarket segment is estimated to account for a larger share of the overall market in 2020. Lubricants are replenished frequently, depending on the operating hours of the aircraft. The aftermarket segment includes various stages of maintenance, such as base maintenance, line maintenance, and different-level checks that an aircraft undergoes during its lifetime. The high growth of the segment is attributed to the increasing deliveries of aircraft in the region and rising passenger traffic [7].

Today the major players in the aviation lubricants market are Exxon Mobil Corporation, Aerospace Lubricants, Inc., The Chemours Company, Royal Dutch Shell plc, NYCO, LANXESS, LUKOIL, Nye Lubricants, Inc., Eastman Chemical Company, ROCOL, and JET-LUBE [12].

The world production of lubricants (for aviation and other industries) are:

- oils - about 42.8 million tons/year (2019);

- greases - more than 1.0 million tons/year;

- cutting fluids - about 1.5 million tons/year. 
Mineral oils account for $90 \%$ of total world oil production, synthetic - only $10 \%$. Automotive oils account for $56.0 \%$ of the total oil production, industrial (including aviation) oils $-26.2 \%$, process oils $-9.4 \%$, cutting fluids - $5.3 \%$, greases $-3.1 \%$ [14].

For example, Ukraine uses about 400 thousand tons of oil. The largest share in total consumption is accounted for by motor $(74.1 \%)$ and industrial $(21.4 \%)$ oils [14, 15].

3.2. Properties and functions of aviation lubricants. Lubricants perform complex of important functions in jet engines. The most important is absorbing and removing heat from bearings. Heat then gets passed from the lubricant to the fuel, heating the fuel and cooling the lubricant. This fuel-to-oil heat exchange is important as the fuel tanks on aircraft are routinely exposed to extremely cold temperatures at high altitudes.

Lubricants also reduce friction between moving metal details and are expected to do this despite wide variations in outside temperatures. Turbine oils are expected to be fluid at low temperatures with pour points below $54{ }^{\circ} \mathrm{C}$. They must also have low volatility at high temperatures because they will be exposed to temperatures of about $200{ }^{\circ} \mathrm{C}$ and have flash points greater than $246{ }^{\circ} \mathrm{C}[3,14]$.

Aviation lubricants must also carry various admixtures and debris to oil filters for removal. They should protect engine parts from corrosion and resist and prevent deposit formation. At the same time, they need to prevent elastomeric seals, O-rings, gaskets and other engine seals from breaking down, which can be particularly challenging based on the chemistry [3, 15].

Aviation greases are also used in commercial aviation in many airframe applications as a lubricant. For example, it lubricates drive screws in hydraulically powered actuators that move flight controls and landing gears, trackways for flaps, ailerons, leading-edge slats, and rudder and elevator linkages. Low-temperature performance is critical for aviation. At altitudes of $10,000 \mathrm{~m}$, the air temperatures can be $-40{ }^{\circ} \mathrm{C}$ to $-70{ }^{\circ} \mathrm{C}$. Overall, airframe grease must work has to function from $-73{ }^{\circ} \mathrm{C}$ to $121{ }^{\circ} \mathrm{C}$ [3].

\subsection{Mechanisms of properties deterioration of aviation} lubricants. A little part of the lubricants (10-20\%) used during the operation of the equipment is irretrievably lost to soot, evaporation, drift, ducts and leaks. The main part of them (80-90\%) undergoes significant changes in composition and properties during use: from simple contamination with external impurities and internal wear products to deep chemical transformations. As a result, they undergo significant changes: flooding, contamination with mechanical impurities, profound chemical changes, and therefore up to $80 \%$ of these volumes of oils are converted into waste [16, 17].

During use and storage, the quality of the oil changes, the nature and depth of which depend on the operating conditions, storage and properties of the oil itself.

The reasons for the deterioration of the properties of oils can be thermal decomposition, oxidation, polymerization and condensation of hydrocarbons, charring, fuel dilution, contamination with inorganic particles, flooding. As a result, asphaltene-resinous substances, coke and soot, various salts, acids, surfactants, as well as various types of pollution and water accumulate in the oils - the oils age.

During long-term storage, the quality of oils can deteriorate significantly. The main factors that determine the change in the physicochemical properties of mineral oils during storage are temperature, humidity, circulation and air pollution, exposure to sunlight. These factors are determined primarily by the location of the warehouse and the type of storage. The influence of some of these factors significantly depends on the composition and properties of oils, which must be taken into account when laying for long-term storage. The type and condition of the tank also have a great influence on the safety of oils [15, 17].

The oil must be chemically resistant to oxygen oxidation of air at high temperatures, as well as not change its properties during transportation and storage. It must not only be stable with respect to air oxygen, but also minimally change the quality during operation under the action of high temperature (without decomposition), pressure, moisture [15].

Viscosity and temperature dependence of viscosity are also important indicators of oil quality. Insufficient fluidity at low temperatures complicates and sometimes makes it impossible to use oils in winter conditions. In addition, depending on the operating conditions, specific requirements apply to oils, such as increased lubricity of oils for gears, demulsifying ability of turbine oils (turbine oil in the case of water entering the oil system must be able to quickly and completely separate from water).

The number of indicators characterizing the quality of oils is quite large, which complicates the assessment of its suitability for further use. In this regard, usually seek to choose for each type of oil and its application integrated indicators that most fully characterize the quality of oils, and set for these indicators defective parameters.

Depending on the base oils and additives, as well as the operating conditions, the oxidation oils contain acidic and/or alkaline products. Total alkaline number (TBN) or total acid number (TAN) is analyzed in the laboratory. The value of these indicators characterizes the amount of acidic (alkaline) products that are needed to neutralize the oil. The acid number is measured in $\mathrm{mg} \mathrm{KOH} / \mathrm{g}[1,9]$.

Alkaline number is an indicator that characterizes the ability of oil to convert acidic products formed by fuel combustion and oxidation of oil into neutral compounds. Characterizes the cleaning and dispersing properties of oil. Under the cleaning effect is understood the ability of the oil to prevent the adhesion of contaminants to the surfaces of engine parts. Dispersion property - the ability of oil not to increase the particles of contaminant mixtures and keep them in suspension.

Among the indicators of oil quality for modern engines, their alkaline number is important due to the presence of highly alkaline detergents in oils. Detergents are used to neutralize acidic products in the oil that accumulate over time during combustion in fuel engines (especially sulfur) and oil oxidation.

It is known that the accumulation of acidic products in the running oil increases the wear of engine parts. In this regard, the period of change of the working oil is regulated by the change of its alkaline number $[1,9,16]$.

During operation, thermal oxidative processes are actively developed in motor oils, as a result of which the acidity of oils significantly increases. Its growth is due to the operation of additives contained in the oil. After some time, the acidity reaches a value at which the oil can no longer perform its functions and must be replaced. Thus, the acid number is one of the most objective indicators of oil performance.

In addition, it is known that some additives for motor oils have an alkaline base, and others - acid. When these 
additives are introduced into the composition of the oil, they interact with each other to establish a dynamic equilibrium. That is why the acid number can also serve as a measure of the compatibility of functional additives and compositions [1, 10].

Thus, the condition of working oils can be theoretically characterized by the change in acid number - one of the most informative indicators of their quality.

In the general case, the processes in oils can be characterized by the entropy derivative or its change relative to the initial value. The entropy derivative, determined by the rate of its change, is expressed by the ratio [14]:

$$
\frac{\partial S}{\partial \tau}=-\frac{v A}{T},
$$

where $S$ - entropy; $\tau$ - time; $v$ - rate of the chemical reaction; $A$ - affinity of the reaction; $T$ - temperature.

The rate of reaction is related to the degree or completeness $\xi$ of its development by the ratio [14]:

$$
v \sim \frac{\partial \xi}{\partial \tau}
$$

The value of $\xi$ varies from 0 to 1 .

It is possible to assume that $\xi=0$ corresponds to the initial state of the oil, and $\xi=1$ - the state at the time of which all possible transformations took place in the oil. It is possible that the loss of oil performance (and hence reduce the reliability of the lubricating equipment) corresponds to a critical value of $\xi_{c r}$, which is less than 1 , i. e. $0<\xi_{c r}<1$.

The characteristics of oils can be expressed by specific indicators that can be reliably monitored in practice. Such informative indicators fully include the acid number of the oil.

Analysis of experimental data shows that in the general case, the change in the acid number $C_{k}$ of oils in time $\tau$ can be described by the logistic function [14]:

$$
C_{k}=\frac{C_{\max }}{\left(1+a e^{-b \tau}\right)},
$$

where $C_{\max }$ is the maximum acid number of the oil in which all possible thermochemical interactions took place by a certain point in time $\tau ; a$ - an indicator of the effectiveness of additives in the process of inhibiting thermochemical transformations of the oil base; $b$ is an indicator that characterizes the operability of additives.

Despite the relatively high informativeness of the TAN, in practice to determine the condition of oils usually use the number of neutralization - TBN $[10,14]$.

3.4. Environmental and economic issues of waste aviation lubricants disposal. Environmentally safe utilization of waste oils involves their use to obtain commercial products for various purposes: greases, cutting fluids, conservation lubricants and more. The main place in solving the problem is occupied by waste oils, the resources of which are estimated at about $50 \%$ of the consumption of commercial products, while waste oil oils account for $\sim 30 \%$ of all oil waste. At the same time, the technique of purification and regeneration of used synthetic and vegetable oils is being developed. Methods of oil processing can be systematized into the following: physical, physico-chemical, chemical and combined. The most accessible method of cleaning oil is physical, which includes sludge, separation in centrifuges, filtration and washing with water [2, 5, 17].

In addition to reducing the amount of harmful emissions into the environment, the regeneration and reuse of oils will provide additional profits. If the process is properly organized, the cost of reconstituted oils will be 40-70\% lower than the cost of commercial oils with almost the same quality. In industrialized countries, the share of regenerated oils in total production is about $30 \%$ [2].

The most important problem is the accumulation of waste oils. These waste oils are divided into groups: waste motor oils (WMO), waste industrial oils (WIO) and of waste oil mixtures (WOM). WMO and WIO are used as raw materials for regeneration and purification, WOM are processed at the refinery in a mixture with crude oil. The possibility of accumulation of motor and industrial oils is up to $20-40 \%$, transformer $-80-90 \%$ of the volume of waste products. The global accumulation of WOM is $\sim 15$ million tons/year, with the dominant part (70-90 \%) being burned as a fuel component. In Europe, the accumulation of WOM is the largest: $\sim 56-58 \%$ (up to 1.6 million tons/year). And in Europe, only up to $25 \%$ of WMO is dumped, up to $75 \%$ is collected, of which $25 \%$ is regenerated, $49 \%$ is used as fuel and $1 \%$ is destroyed [14].

3.5. Methods for waste lubricating materials disposal. Different methods are used for utilization of WOM (Fig. 1, 2) [14, 17]. Methods for processing waste oils are rapidly developing today. They allow to get a greater economic effect than from their combustion in heating systems. This is co-processing in a mixture with oil at refineries and targeted processing by thermal cracking or vacuum method. The existing mini-unit «Consum-Diesel», the operation of which is based on the processes of thermal cracking and distillation, makes it possible to obtain from used engine oil: associated gas (3-4\%), gasoline (4-5\%), diesel fuel (80-85\%), as well as semi-coke (3-5\%) [8]. Despite such a variety of areas for the use of used engine oils, in our opinion, it is more economically feasible to develop and implement schemes for the processing of used engine oils, which make it possible to obtain basic components for the production of motor and gear oils, greases. Disposal of waste oil is a positive factor for the environment and the economy for several reasons [14]:

1. Regeneration of waste oil requires three times less energy than is used to obtain base oils in crude oil refining.

2 . To produce 1 liter of new high quality lubricant requires 67.2 liters of crude oil and only 1.6 liters of waste oil.

3. One liter of waste oil, prepared for use as fuel, contains about $40 \mathrm{MJ}$ of energy.

Today WOM are exposed to $[10,18]$ :

1) reprocessing as a mixture, mainly of petroleum oils, sometimes - with minor admixtures of synthetic oils and cutting fluids, to obtain basic components;

2) separate regeneration by brands to obtain oils for the purpose. In this case, the removal of aging products and contaminants without destruction and separation of the missing additives, the number of which is added at the final stage of preparation of commercial oils;

3 ) processing of mixtures of waste oils or purification of individual waste products in order to obtain furnace fuel;

4) use as low-quality fuel or components of other petroleum fuels. 


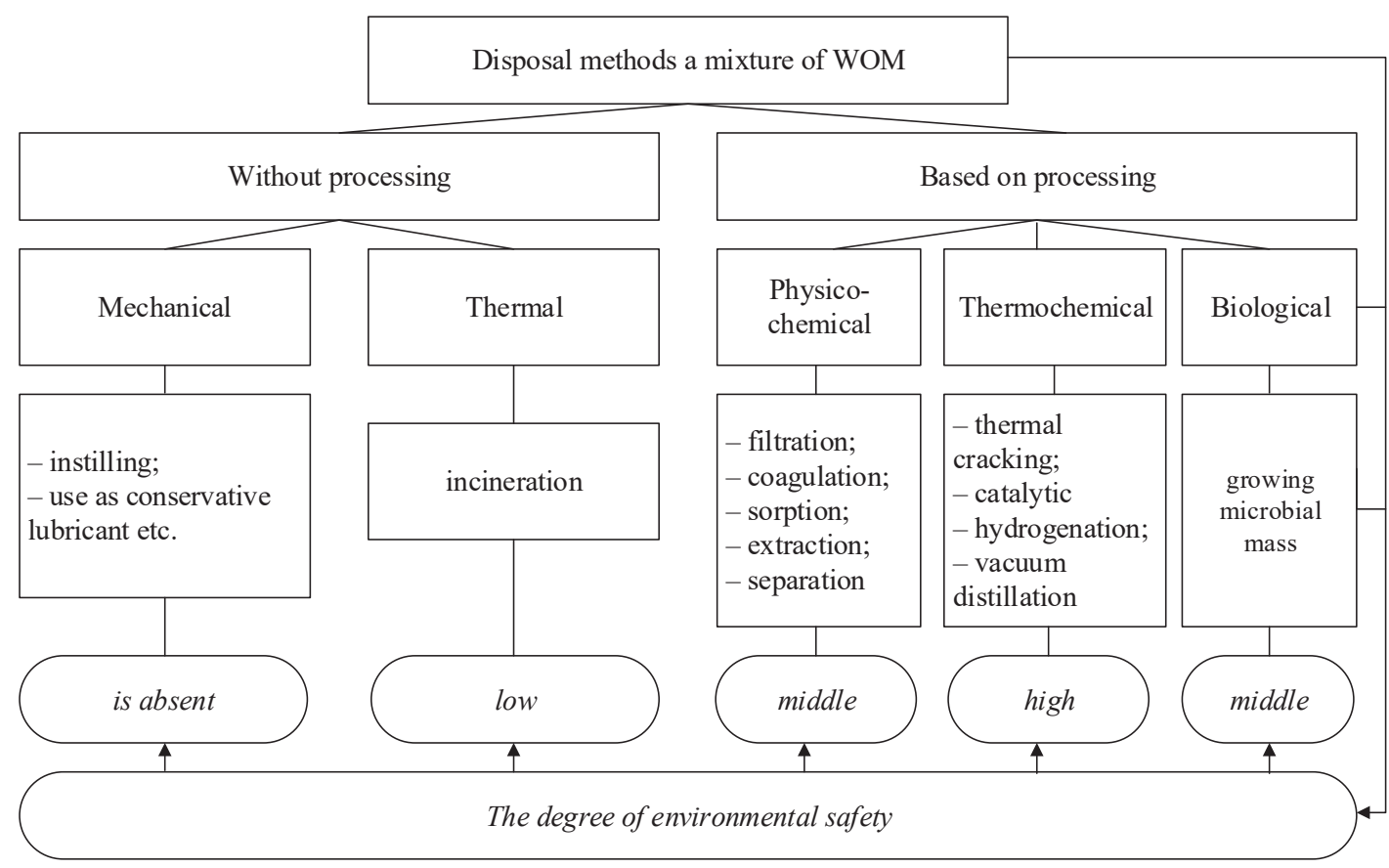

Fig. 1. Generalized systematization of waste oil materials utilization methods $[14,17]$

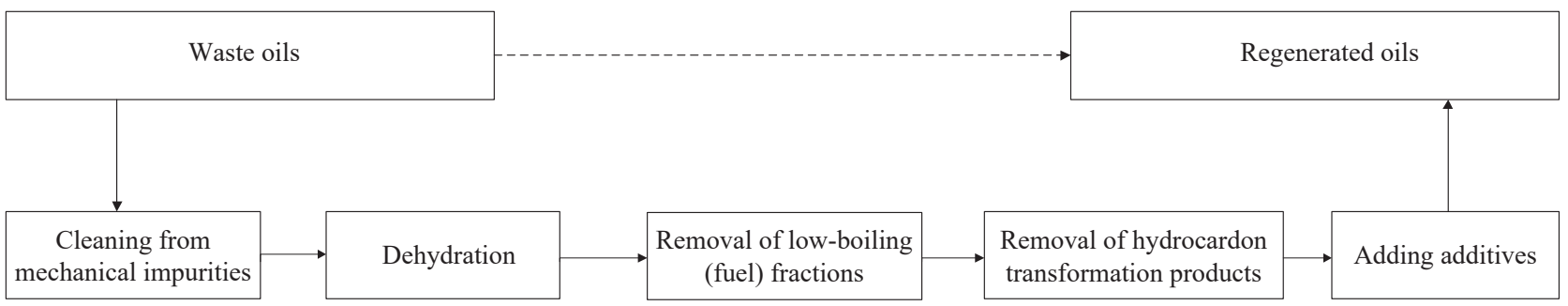

Fig. 2. Stages of the oil regeneration process $[14,17]$

Among the modern methods of WOM regeneration, physical methods predominate - sludge, centrifugation, filtration, vacuum drying [19].

It is believed that with an annual consumption of more than 10 tons of oils by the company, capital investments for cleaning and regeneration of IEDs at the place of consumption pay off in full.

3.6. Recycling. The largest volumes are processed into mixtures of WOM, which are collected centrally at industrial enterprises. The main problem here is the organization of raw material collection. In the world, the total share of base oils obtained by recycling of WOM does not exceed $5 \%$ of fresh consumption $[18,19]$.

A significant part of WOM consists of motor oils, which contain mainly paraffinic, naphthenic and aromatic hydrocarbons, additives, aging products and metals. Among the various industrial recycling processes, the following purification methods predominate: adsorption, extraction, hydrotreating, thin-film evaporation, ultrafiltration. Today, the bulk of the collected spent WOM is burned or merged into the ground. Only a small part is recyclable, mainly for recycling into fresh produce [17, 20].

Among the various industrial recycling processes, the following methods predominate: adsorption, extraction, hydrotreating, thin-film evaporation, ultrafiltration. The most important place in terms of the amount of raw materials processed belongs to processes using sulfuric acid, among which until recently the main ones were $[15,17]$ :

- acid-contact cleaning;

- acid-contact purification combined with atmospheric vacuum;

- distillation;

- process of the French Petroleum Institute (IFP);

- processes with the stage of heat treatment of raw materials;

- Meinken process (Germany).

There is a tendency to increase the importance of technologies using thermal cracking, which is more flexible in relation to the processing of various hydrocarbons.

For extraction purification they mainly use propane, the main disadvantage of which is the low boiling point, which requires high operating pressure and special equipment (pumps, mixers). Propane is quite dangerous during operation and storage; while production losses, especially in hot climates, are quite high [15, 19].

Processes that previously ranked second in terms of industrial application using adsorption purification (contact or percolation method) as the main stage, recede into the background due to the formation of a large number of spent sorbents. The disadvantages of such processes are the lack of control over the viscosity and boiling range of the product and significant losses of oils with sorbent. Certain difficulties arise due to the need to dispose of a large amount of spent sorbent [14, 15]. 
Hydrogenation processes are becoming more common in the field of recycling of spent WOM and are now becoming a common stage of the flow scheme. This is due to the wide possibilities of obtaining high-quality oils, increasing their yield, and the greater environmental friendliness of the process compared to all of the above. Hydrotreating is usually combined with vacuum distillation. In some cases, hydrogenation processes are used to refine the target products of processing. Hydrotreating is also combined with propane extraction [11, 14].

Thin-film evaporation is considered to be a very promising process of secondary processing of motor oils. The raw material, after removal of water and light fuel fractions, is evaporated in a thin-film evaporator under conditions of deep vacuum $(0.133-0.266 \mathrm{kPa})$, at a temperature of $350{ }^{\circ} \mathrm{C}$. the non-evaporating part contains solid contaminants, resinous substances, metals and is removed from the bottom of the evaporator (can be used in the production of asphalt). The oil fractions are treated with fuller's soil or subjected to hydrotreating. The most important disadvantage of the solid waste process is the need to maintain a vacuum and high temperature, which requires the use of a special coolant. The rotating elements of the evaporator often fail and need to be changed frequently [11, 15].

Processing of WOMs and their use as fuel have become the most widespread. In terms of energy characteristics, waste oils are close to petroleum fuels. The following are the values of the heat of combustion (lower) of a number of products, $\mathrm{MJ} / \mathrm{kg}$ [17]:

- naval and furnace fuel oils - 40-42;

- waste motor oils (motor) - 45;

- waste synthetic oils based on esters - 39;

- the same, based on polyalkylene glycol - 23-26.

WOMs are not used for their intended purpose, if they are not subject to regeneration and processing. WOMs can be used to lubricate coarse friction joints, such as reinforced concrete molds; as reagents in flotation processing of ore in concentrators; for prevention of freezing and sticking of loose freights to walls of cars at low temperatures. The disadvantage of such use of WOMs is the possibility of environmental pollution by environmentally hazardous products.

Purified WOM or recycled base oils can be used in the production of greases as a component of the dispersion medium.

Purification and regeneration of synthetic oils due to their high cost is especially important. In addition, many synthetic oils (polychlorinated biphenyls, phosphoric acid esters) pose a significant risk to humans and the environment [14].

Methods of regeneration of waste synthetic oils are chosen depending on their chemical composition. They are similar to those used in the regeneration of petroleum oils: filtration, vacuum distillation, sulfuric acid purification, selective and hydrotreating, etc.

For purification and regeneration of cutting fluids use complex schemes with the use of gravity tanks, magnetic separators and coagulators, hydrocyclones, various filter designs, flotators and separators, coagulants and reagents for the deposition of impurities and the subsequent introduction of the necessary impurities.

Environmentally friendly lubricants currently include esters based on synthetic or vegetable raw materials, refined vegetable oils and their transesterification products.

At neutralization of such WOM it is necessary to adhere to certain rules: to burn the fulfilled vegetable oils at special plants on destruction of waste, dumping in the sewerage or in open reservoirs to carry out at cultivation accordingly $1: 2000$ and 1:20000.

WOM reprocessing technology may include vacuum distillation of waste oils, which allows to obtain primary quality oil as a base oil or raw material for the production of technical products, alkaline neutralization, washing of neutralized oil with water and adsorption purification. A separate collection of biodegradable liquids is required to maintain a high level of their performance properties.

Waste rapeseed and other vegetable oils can be used as fuel, including in a mixture with waste petroleum oils. Conversion (transesterification) into methyl esters used as diesel fuel («biodiesel») is possible [8].

After additional purification and introduction of new additives the regenerated oils may be used as lubricants in different branches of national economy.

\section{Conclusions}

Concluding the presented material is should be said that aviation oils production and disposal industry are closely connected. Rapidly evolving aviation industry causes rising demand in sustainable aviation oils that in its turn result in formation and accumulation of waste oils, which have to be properly disposed.

During the study the physical-chemical properties of aviation oils were analyzed, as well as processes, which take place in oils during its storage and use. It was found that oils loose its quality during storage and operation irreversibly. The main parameter that describes quality loss is acid number, and its change can be described mathematically.

In a result of the study it is shown that producing high quality oils can provide durability and reliability of aircraft engines and parts and prolong operation time of aviation lubrication materials.

In a result of the study the main approaches to waste aviation oils disposal were determined and formulated. Among them are recycling methods that allow to use waste oils as a feedstock for new products manufacturing and purification and regeneration methods, which allow secondary use of waste oils.

It is shown that recycling technologies allow producing conditioned oils from waste, which are identical in quality to commercial. The cost of production of such oils is twice lower than the cost of production of commercial oil.

Results of the study will be interesting and useful for professionals involved in sphere of lubricating materials production, use and utilization, in particular in aviation sector. At the same time the study may be used for further development of particular technologies for waste oil disposal.

\section{Acknowledgments}

This work is supported by the EFOP-3.6.1-16-2016-00003 project. The project is co-financed by the European Union.

\section{References}

1. Boichenko, S., Yakovlieva, A., Lejda, K., Kurdel, P. (2020) Modern Road Transport's Operational materials. Technical University of Košice, 279.

2. Hester, R. E., Harrison, R. M. (2004). Transport and the Environment. Royal Society of Chemistry, 160. 
3. Sniderman, D. (2020). What it Takes to be a Commercial Aviation Jet Engine Lubricant. Machine Design. Available at: https://www.machinedesign.com/mechanical-motion-systems/article/21124388/ what-it-takes-to-be-a-commercial-aviation-jet-engine-lubricant

4. Gong, H., Yu, C., Zhang, L., Xie, G., Guo, D., Luo, J. (2020). Intelligent lubricating materials: A review. Composites Part B: Engineering, 202, 108450. doi: http://doi.org/10.1016/j.compositesb.2020.108450

5. Kulyk, M. I. (2015). Utilization of waste motor oils: environmental-and economical aspect. Man and the environment. Problems of neoecology, 1-2, 122-128.

6. Małuszyńska, I., Bielecki, B., Wiktorowicz, A., Małuszyński, M. J. (2012). Recykling materiałowy i surowcowy odpadów samochodowych. Inżynieria Ekologiczna, 28, 111-118.

7. Aviation Lubricants Market. An annual report. Available at: https:// www.marketsandmarkets.com/pdfdownloadNew.asp?id=37676118

8. Demirbas, A., Baluabaid, M. A., Kabli, M., Ahmad, W. (2015). Diesel Fuel From Waste Lubricating Oil by Pyrolitic Distillation. Petroleum Science and Technology, 33 (2), 129-138. doi: http://doi.org/10.1080/10916466.2014.955921

9. Sethuramiah, A. (Ed.) (2003). Lubricant technology a survey. Vol. 42. Tribology Series. Elsevier, 35-65. doi: http://doi.org/ 10.1016/s0167-8922(03)80005-6

10. Bartm J. C. J., Gucciardi, E., Cavallaro, S.; Bartm J. C. J., Gucciardi, E., Cavallaro, S. (Eds.) (2013). Lubricant use and disposal. Woodhead Publishing Series in Energy, Biolubricants. Woodhead Publishing, 755-823. doi: http://doi.org/10.1533/9780857096326.755

11. Tsai, W.-T. (2011). An analysis of used lubricant recycling, energy utilization and its environmental benefit in Taiwan. Energy, 36 (7), 4333-4339. doi: http://doi.org/10.1016/j.energy.2011.04.008

12. Aviation Lubricants Market by Type, Technology, End User, Application, and by Platform: Global Opportunity Analysis and Industry Forecast, 2020-2027. Available at: https://www.alliedmarketresearch.com/aviation-lubricants-market-A07930

13. Boichenko, S. V., Yakovlieva, A. V., Vovk, O. O., Radomska, M. M., Cherniak, L. M., Shkilniuk, I. O. (2019). Fundamentals of Chemmotology. Kyiv: National Aviation University, 296. doi: http://doi.org/10.18372/40022
14. Boichenko, S., Spirkin, V. (2009). Introduction into chemmotology of fuels and lubricants. Part 1. Odessa: Astroprint, 236.

15. Evdokimov, A. Iu., Fuks, I. G., Liubinin, I. A. (2012). Smazochnye materialy v tekhnosfere i biosfere: ekologicheskii aspekt. Kyiv: Atika, 292.

16. Fuks, I., Spirkin, V., Shabalina, T. (2004). Fundumentals of chemmotology. Chemmotology in oil and gas processing. Moscow: Neft i gaz publishing, 280.

17. Boichenko, S. V., Ivanchenko, O. V., Leida Kazymir, Frolov, V. F., Yakovlieva, A. V. (2019). Ekolohistyka, retsyklinh i utylizatsiia transportu. Kyiv: NAU, 266.

18. Grigorov, A. B. (2012). Complex processing of used engine oils. Energy saving. Energy. Energy audit, 5 (99), 40-44.

19. Chaika, O. H., Kovalchuk, O. Z., Chaika, Yu. A. (2009). Monitorynh utvorennia vidpratsovanykh olyv v Ukraini. Visnyk Natsionalnoho universytetu «Lvivska politekhnika», 644, 221-224.

20. Chaika, O. G., Khomko, N. Yu., Ilkiv, I. M., Malik, Yu. O. (2010). Development of a set of measures for the implementation of the system of harvesting waste oils. Bulletin of the National University «Lviv Polytechnic», 667, 320-322.

Sergii Boichenko, Doctor of Technical Sciences, Professor, Leading Researcher, National Aviation University, Kyiv, Ukraine, ORCID: https:// orcid.org/0000-0002-2489-4980, e-mail: chemmotology@ukr.net

Anna Yakovlieva, PhD, Leading Researcher, National Aviation University, Kyiv, Ukraine, ORCID: https://orcid.org/0000-00027618-7129, e-mail: anna.yakovlieva@nau.edu.ua

Utku Kale, PhD, Assistant Professor, Department of Aeronautics, and Naval Architecture, Budapest University of Technology and Economics, Budapest, Hungary, ORCID: https://orcid.org/00000001-9178-5138,e-mail: ukale@vrht.bme.hu

András Nagy, PhD, Associate Professor, Department of Mechanical Engineering, University of Dunaújváros, Dunaújváros, Hungary, ORCID: https://orcid.org/0000-0002-5665-4324, e-mail: nagy.andras@uniduna.hu 